\title{
PENDEKATAN SISTEM DALAM PENANGANAN KESELAMATAN JALAN
}

\author{
Systems Approach in Road Safety Handling \\ Vita Mayastinasari \\ Sekolah Tinggi Ilmu Kepolisian \\ Jalan Tirtayasa Raya No.6, Kebayoran Baru \\ Jakarta Selatan, DKI Jakarta \\ mamayovi@gmail.com
}

\begin{abstract}
Various traffic safety efforts aimed to reduce the number of traffic accident victims on the road. Traffic safety is a program to reduce the number of accidents, either the consequences. The tendency of road accident causes is a human factor, therefore is needed a systematic approach to handle traffic safety that includes four aspects, that is 1) Process; 2) Infrastructure; 3) Management; 4) Coordination and integration. The safer road can not be achieved if only using the strategy, but the capacity of the institution is needed by coordination and integration amongst the ministries of the institution. Coordination and integration as a form of synergy among the ministries of the institution to handle the road safety conducted by sharing the role to handle various road safety-related areas by using the Information Resources Information System-IRIS.
\end{abstract}

Keywords: system approach, road safety handling, institutional capacity, synergy, information resource system.

\begin{abstract}
Abstrak
Berbagai upaya keselamatan lalu lintas yang bertujuan menurunkan korban kecelakaan lalu lintas di jalan. Keselamatan lalu lintas merupakan suatu program untuk menurunkan angka kecelakaan beserta seluruh akibatnya. Kecenderungan penyebab kecelakaan lalu lintas adalah faktor manusia, sehingga diperlukan pendekatan sistem dalam penanganan keselamatan jalan yang mencakup empat aspek, yaitu: 1) Proses; 2) Infrastruktur; 3) Manajemen; 4) Koordinasi dan integrasi. Keselamatan jalan tidak dapat terwujud hanya dengan menggunakan strategi, namun dibutuhkan kapasitas kelembagaan melalui koordinasi dan integrasi antar kementerian lembaga. Koordinasi dan integrasi sebagai wujud sinergitas antar kementerian lembaga dalam penanganan keselamatan jalan dilakukan dengan berbagi peran dalam menangani berbagai bidang yang terkait keselamatan jalan dengan menggunakan sistem informasi sumber daya informasi (Information Resources Information System-IRIS).
\end{abstract}

Kata kunci: pendekatan sistem, penanganan keselamat jalan, kapasitas kelembagaan, sinergitas, sistem informasi sumber daya informasi.

\section{PENDAHULUAN}

Berdasarkan data Integreated Road safety Management Sytem (IRSMS), laporan periodik dari 1 januari 2013 sampai 31 desember 2017, diketahui bahwa jumlah total kejadian kecelakaan lalu lintas sebanyak 485156 (189\%); jumlah kejadian kecelakaan lalu lintas berakibat korban meninggal dunia sebanyak 112.218 (245\%); total nilai rugi material kendaraan Rp. 1.101.407.912.434 (165\%); total korban meninggal dunia sebanyak 132.695 orang $(230 \%)$; total korban luka berat sebanyak 104.762 orang $(84 \%)$; total korban luka ringan sebanyak 5.483 .36 orang (222\%). Data diilustrasikan pada gambar 1 sampai dengan 5. 
Traffic Accident Research Centre

Laporan Periodik

01 Januari 2013 - 31 Desember 2017

\begin{tabular}{|c|c|c|c|}
\hline \multicolumn{4}{|c|}{ Semua Polda } \\
\hline Jumlah Total Kejadian Laka: & 485156 & $(189 \%)$ & \\
\hline Jumlah Kejadian Laka berakibat korban MD: & 112218 & $(245 \%)$ & \\
\hline Total Nilai Rugi Material Kendaraan, Rp.: & $1,101,407,912,434$ & $(165 \%)$ & \\
\hline Total Korban Meninggal Dunia: & 132695 & $(230 \%)$ & \\
\hline Total Korban Luka Berat: & 104762 & $(84 \%)$ & \\
\hline Total Korban Luka Ringan: & 548336 & $(222 \%)$ & \\
\hline \multicolumn{3}{|c|}{$\begin{array}{c}\text { Ket: Perubahan terhadap } 02 \text { Januari } 2008 \text { - } 31 \text { Desember } 2012 \text { dalam tanda } \\
\text { kurung }\end{array}$} & \\
\hline \multicolumn{3}{|l|}{ Laporan Yang Belum Selesai atau Belum Divalidasi } & $\begin{array}{c}15 / 03 / 2018 \\
16: 33\end{array}$ \\
\hline Tidak terhitung di statistik: & & 5315 & \\
\hline
\end{tabular}

Gambar 1. Laporan periodik

Sumber: Integreated Road safety Management Sytem (IRSMS)

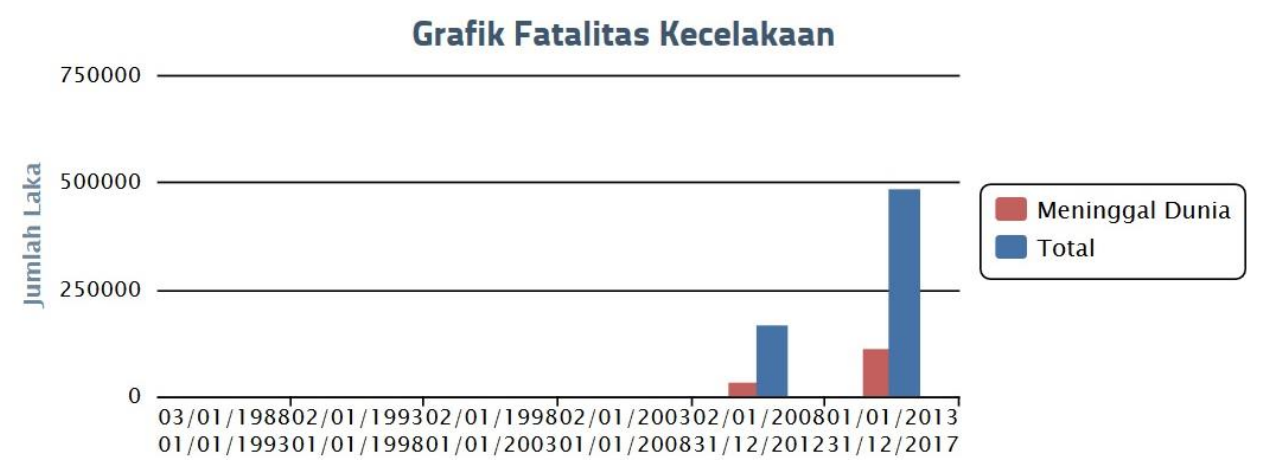

Gambar 2. Grafik fatalitas kecelakaan

Sumber: Integreated Road safety Management Sytem (IRSMS)

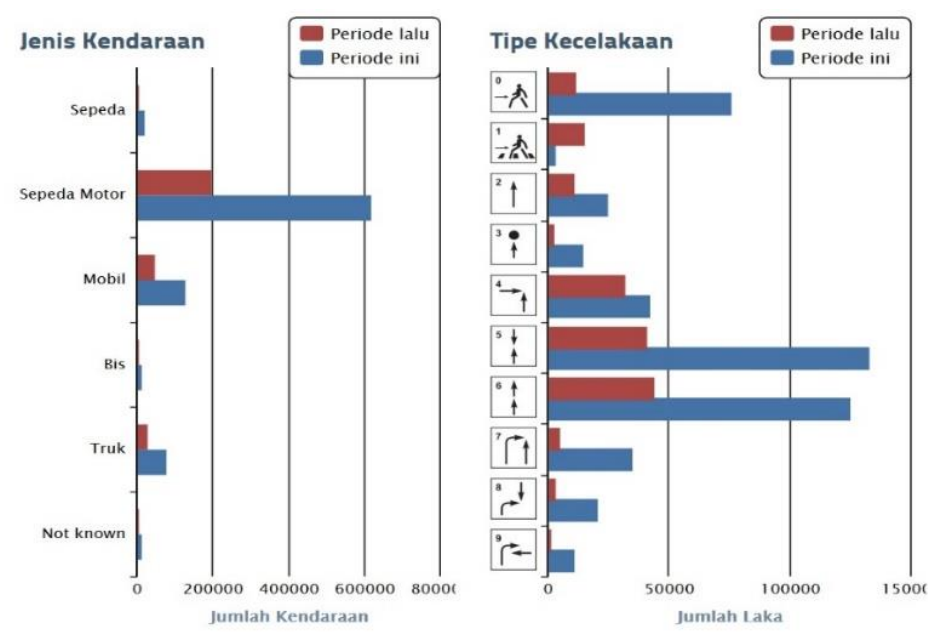

Gambar 3. Diagram jenis kendaraan dan tipe kecelakaan Sumber: Integreated Road safety Management Sytem (IRSMS) 


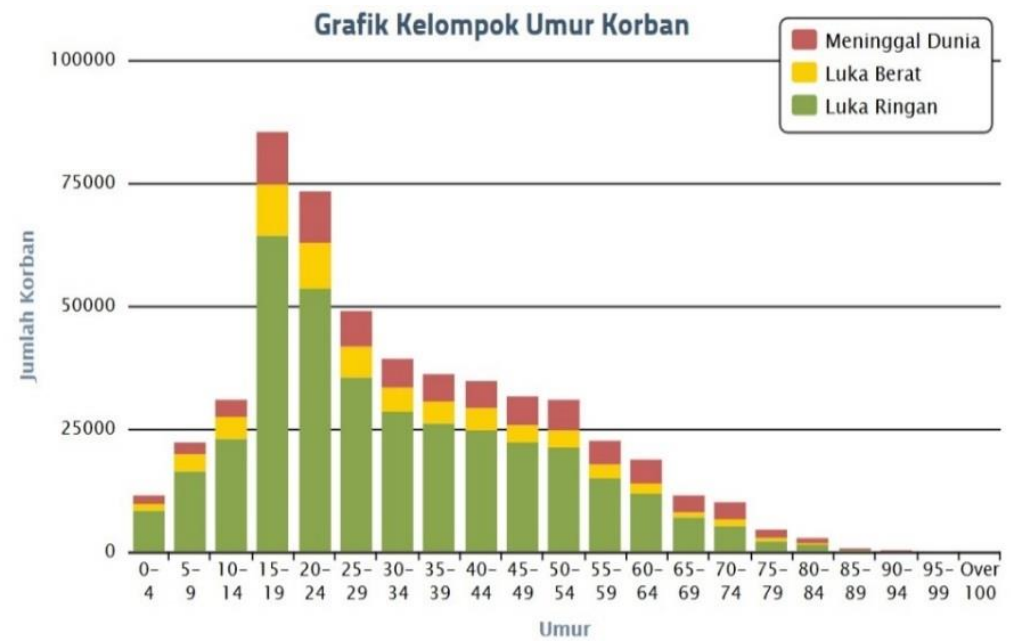

Gambar 4. Grafik fatalitas kecelakaan

Sumber: Integreated Road safety Management Sytem (IRSMS)

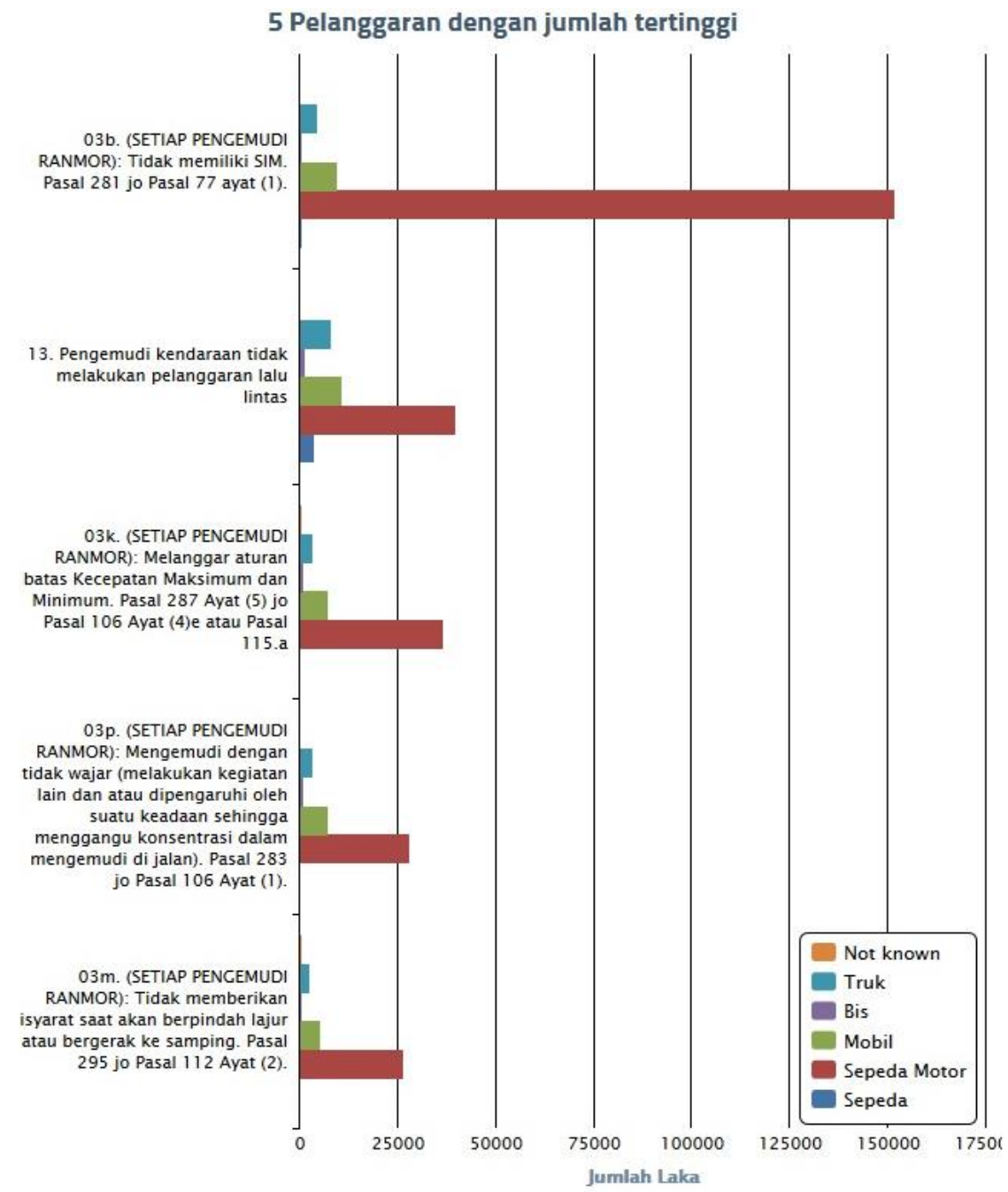

Gambar 5. Diagram pelanggaran

Sumber: Integreated Road safety Management Sytem (IRSMS) 
Oleh sebab itu diperlukan berbagai upaya keselamatan lalu lintas yang bertujuan menurunkan korban kecelakaan lalu-lintas di jalan melalui pendekatan sistem. Keselamatan lalu lintas merupakan suatu program untuk menurunkan angka kecelakaan beserta seluruh akibatnya. Berpikir kesisteman akan menghasilkan pola pikir (mode of throught) lintas disiplin atau interdisiplin. Pendekatan sistem bersifat holistik dan kontekstual serta merupakan pemikiran yang berkaitan (sistemik) dan sistematik. Pendekatan sistem mendorong keseimbangan antara perspektif jangka pendek dan jangka panjang, mengakui adanya dinamika, kompleksitas dan sifat saling bergantung antar komponen sistem serta memperhatikan kesalingterkaitan antara kejadian yang ada dalam sistem. Pendekatan sistem dalam penanganan keselamatan jalan perlu dilakukan agar penanganannya tepat karena pendekatan sstem memperhatikan proses perubahan, bukan hanya kondisi sesaat (snapshots), mempertimbangkan faktor terukur \& tidak terukur serta memperhatikan keteraturan bagian dan mempertahankan kestabilan.

\section{PEMBAHASAN}

Kecenderungan penyebab kecelakaan lalu lintas adalah faktor manusia, sehingga diperlukan pendekatan sistem dalam penanganan keselamatan jalan yang mencakup empat aspek, yaitu: 1) Proses; 2) Infrastruktur; 3) Manajemen; 4) Koordinasi dan integrasi. Keempat aspek tersebut sejalan dengan teori sistem pengendalian manajemen yang dikemukakan oleh Maciariello and Kirby, secara skematis diilustrasikan Gambar 1.

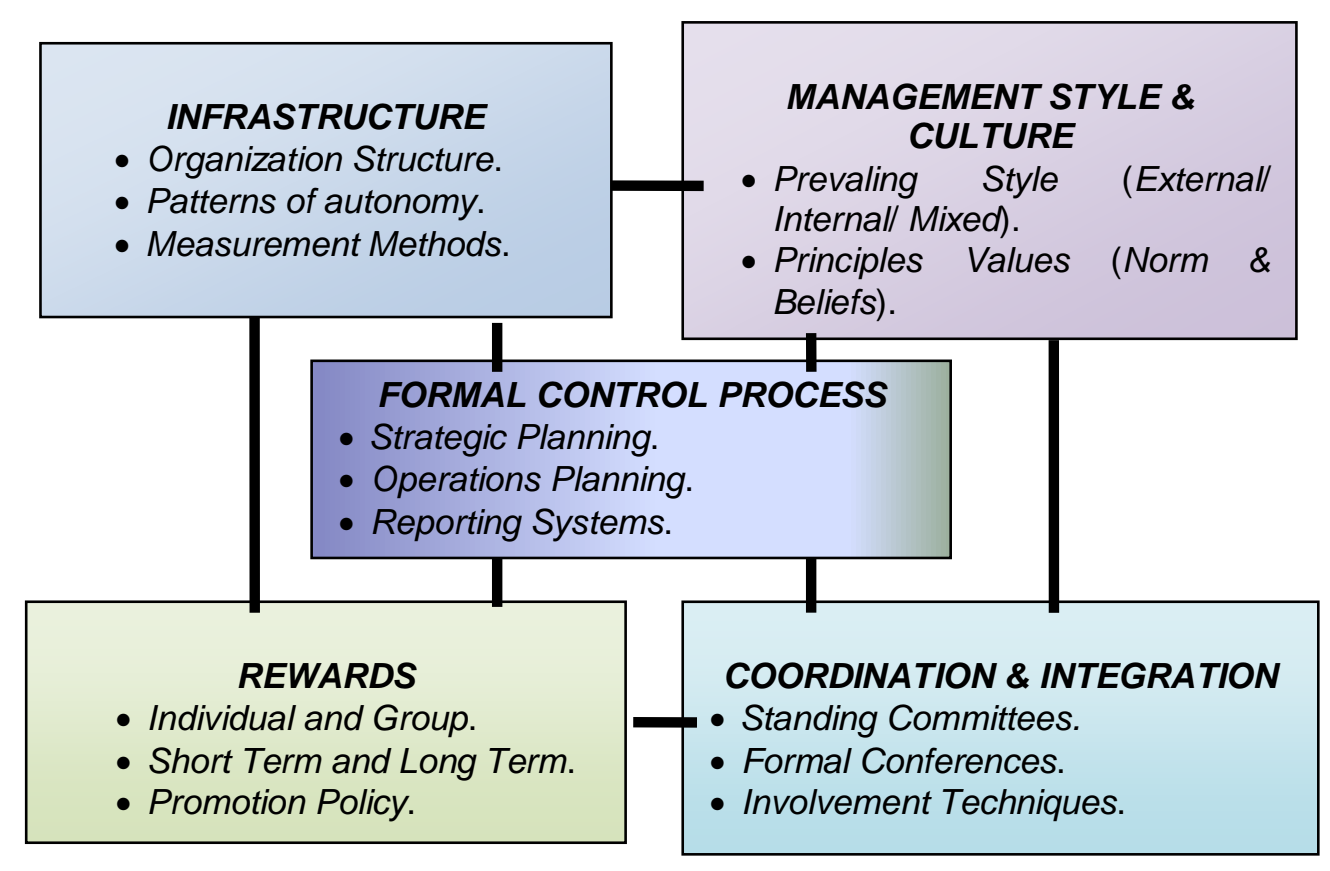

Gambar 6. Formal control systems

Sumber: Maciariello, Joseph A. and Calvin J. Kirby. 1994. Management Control Systems. Second Edition. New Jersey: Englewood Cliffs. P. 9.

Pendekatan sistem merupakan pendekatan yang dapat digunakan untuk memecahkan masalah secara lebih sistematis dan sistemik (menyeluruh) dengan fokus pada pencapaian tujuan. Pendekatan ini digunakan untuk mengelola perubahan dengan menggunakan berbagai teknik untuk mempelajari dan memecahkan berbagai permasalahan secara 
menyeluruh. Permasalahan keselamatan jalan merupakan permasalahan yang kompleks, memerlukan banyak pertimbangan terhadap berbagai faktor yang saling terkait, sehingga diperlukan: kemampuan konseptual, toleransi terhadap ketidakjelasan dan kesadaran terhadap situasi yang saling berkaitan.

Pendekatan sistem dalam penanganan keselamatan jalan bertujuan agar terwujud efisiensi dan efektivitas penanganan keselamatan jalan melaui sinergitas berbagai kementerian dan lembaga yang terkait dengan keselamatan jalan sehingga:

1. Keamanan, keselamatan, ketertiban dan kelancaran lalu lintas (Kamseltibcarlantas) dapat terwujud;

2. Kualitas keselamatan meningkat dan tingkat fatalitas korban kecelakaan lalu lintas menurun;

3. Budaya tertib berlalu lintas dapat terbangun;

4. Berbagai sistem yang mampu meningkatkan kualitas pelayanan dibidang LLAJ dapat terbangun.

Keempat aspek pendekatan sistem dalam penanganan keselamatan jalan mencakup:

\section{Aspek Proses}

Aspek proses mencakup perencanaan strategi, perencanaan operasi dan sistem pelaporan. Perencanaan strategi dalam penanganan keselamatan jalan dilakukan dalam tiga area, yaitu area pendidikan, perbaikan peraturan perundang-undangan dan penegakan hukum. Beberapa hal yang dapat dilakukan dalam area pendidikan adalah: Pendidikan berlalu lintas sejak usia dini, pada saat anak masuk sekolah taman kanak-kanak; Penyuluhan tentang keselamatan jalan melalui media masa; Membangun dan mengefektifkan Pendidikan Keselamatan Lalu Lintas (PPKL). Perbaikan peraturan perundang-undangan dan penegakan hukum dilakukan untuk meminimalisasi dan mencegah pelanggaran lalu lintas serta korban kecelakaan lalu lintas, sehingga terwujud Kamseltibcarlantas. Perbaikan peraturan perundang-undangan diharapkan juga menjangkau industri kendaraan bermotor dalam hal kewajiban melengkapi teknologi kendaraan bermotor untuk meningkatkan keselamatan pengendaranya.

Perencanaan operasi dalam penanganan keselamatan jalan mencakup: peningkatan keselamatan kendaraan, peningkatan jalan dan fasilitas jalan. Peningkatan keselamatan kendaraan dilakukan dengan menyediakan dan meningkatkan kualitas teknologi kendaraan bermotor, antara lain meliputi: Teknologi keselamatan aktif (antara lain: Sistem rem antimacet; Sistem kontrol traksi; Sistem kontrol rem elektronik; Sistem pembantu penglihatan malam hari; Sistem peringatan jarak antar kendaraan); Teknologi keselamatan pasif (antara lain: Kabin dengan rigiditas tinggi; Kantong udara (setir dan dashboard depan); Pintu samping; Bawah dashboard); Sabuk keselamatan (antara lain: Pemberi tensi awal; Pembatas beban); Sandaran kepala aktif

\section{Infrastruktur}

Aspek infrastruktur dalam penanganan keselamatan jalan mencakup struktur, pola otonomi dan metode pengukuran. Struktur penanganan keselamatan jalan merupakan pola pembagian peran antar kementerian lembaga terkait tugas pokok dan fungsinya. Pola otonomi meliputi wewenang masing-masing kementerian lembaga dalam penanganan keselamatan jalan. Metode pengukuran meliputi ukuran-ukuran yang ditetapkan sebagai 
target keselamatan jalan, misalnya target penurunan kecelakaan lalu lintas, target korban meninggal dunia.

\section{Manajemen}

Manajemen penanganan keselamatan jalan dilakukan dengan sinergitas antar kementerian lembaga dan sistem informasi sumber daya informasi. Penggunaan sumber daya informasi secara bersama antar beberapa kementerian lembaga akan mengurangi biaya dan mengoptimalkan data. Optimalisasi data berasal dari integrasi data beberapa kementerian lembaga yang terkait penanganan keselamatan jalan. Sistem informasi sumber daya informasi dibangun dalam sebuah database, sehingga mengurangi biaya.

\section{Koordinasi dan Integrasi}

Keselamatan jalan tidak dapat terwujud hanya dengan menggunakan strategi, namun dibutuhkan kapasitas kelembagaan melalui koordinasi dan integrasi antar kementerian lembaga. Koordinasi dan integrasi sebagai wujud sinergitas antar kementerian lembaga dalam penanganan keselamatan jalan dilakukan dengan berbagi peran dalam penanganan keselamatan jalan, didasarkan pada lima pilar pada Rencana Umum Nasional Keseamatan Lalu Lintas Angkutan Jalan (RUNK LLAJ) ${ }^{1}$ yaitu:

1. Manajemen Keselamatan Jalan (Road Safety Management)

Sinergitas antar kementerian lembaga dalam menjamin pencapaian tujuan dan keberlanjutan program keselamatan jalan memerlukan manajemen keselamatan jalan. Manajemen keselamatan jalan yang dilakukan dengan baik menjamin penyelenggaraan keselamatan jalan secara efektif dan efisien. Bappenas merupakan leader dalam manajemen keselamatan jalan;

2. Jalan yang Berkeselamatan (Saver Road)

Infrastruktur jalan merupakan bagian yang tidak dapat terpisahkan dari keselamatan jalan. Infrastruktur jalan yang baik berpengaruh signifikan terhadap keselamatan jalan. Kementerian lembaga yang menjadi leader pada bidang infrastruktur jalan adalah Direktorat Jenderal Bina Marga, bertanggung jawab menangani keselamatan jalan. Direktorat ini mengambil porsi penanganan keseamatan jalan pada perspektif teknik pembangunan jalan (Unit Rekayasa Keselamatan Jalan/ Road Safety Engineering Unit-RSEU). Infrastruktur jalan yang berkeselamatan dilakukan dengan perbaikan pada berbagai tahap, baik tahap perencanaan, desain, konstruksi dan operasional jalan agar dapat meminimalisasi kesalahan pengguna jalan;

3. Kendaraan yang Berkeselamatan (Saver Vehicle)

Keselamatan jalan juga tidak terlepas dari kondisi kendaraan. Berbagai program terkait kendaraan berkeselamatan antara lain adalah penilaian mobil baru, kelengkapan mobil baru dengan fitur keselamatan; mendorong perusahaan pembuat kendaraan memproduksi kendaraan yang berkeselamatan. Kendaraan yang berkeselamatan secara signifikan akan melindungi pengendara dan korban terhadap resiko kecelakaan yang lebih parah karena sistem kendaraan berjalan dengan baik. Leader kendaraan yang berkeselamatan adalah Kementerian Perhubungan;

\footnotetext{
${ }^{1}$ Laporan Pelaksanaan Who SEA Ministerial Meeting on Accelerating actions for implementation of Decade of Action for Road Safety. Hal 148 sd 149.
} 
4. Perilaku Pengguna Jalan yang Berkeselamatan (Saver Road Users)

Pembentukan perilaku pengguna jalan yang berkeselamatan dilakukan dengan berbagai program pendidikan dan penegakan hukum. Polri memiliki peran pada kedua program tersebut;

5. Penanganan Korban Pasca Kecelakaan (Post Crash Care)

Leader dalam pilar penanganan korban pasca kecelakaan adalah Kementerian Kesehatan. Penanganan korban pasca kecelakaan bertujuan meningkatkan kemampuan ketanggapdaruratan dan penanganan korban.

\section{KESIMPULAN}

Pendekatan sistem dalam penanganan keselamatan jalan mencakup empat aspek, yaitu: 1) Proses; 2) Infrastruktur; 3) Manajemen; 4) Koordinasi dan integrasi. Keselamatan jalan tidak dapat terwujud hanya dengan menggunakan strategi, namun dibutuhkan kapasitas kelembagaan melalui koordinasi dan integrasi antar kementerian lembaga dengan berbagi peran dalam menangani berbagai bidang yang terkait dengan penanganan keselamatan jalan. Pendekatan sistem dalam penanganan keselamatan jalan perlu dilakukan agar penanganannya tepat karena pendekatan sstem memperhatikan proses perubahan, bukan hanya kondisi sesaat (snapshots), mempertimbangkan faktor terukur dan tidak terukur serta memperhatikan keteraturan bagian dan mempertahankan kestabilan. Pendekatan sistem penanganan keselamatan jalan dilakukan dengan sinergitas antar kementerian lembaga dan sistem informasi sumber daya informasi.

\section{DAFTAR PUSTAKA}

Anthony, Robert N., John Dearden and Norton M. Bedford. 1994. Management Control Systems. Terjemahan. Jakarta: Erlangga.

Greenberg, Jerald and Robert A. Baron. 2003. Behavior in Organizations. New Jersey: Prentice Hall.

Maciariello, Joseph A. and Calvin J, Kirby. 1994. Management Control Systems. Second Edition. New Jersey: Englewood Cliffs.

Robbins, Stephen P. 2003. Organizational Behavior. New Jersey: Prentice Hall.

Smith, Jane. 2000. Empowering People. London: Kogan Page Limited.

Laporan Pelaksanaan Who SEA Ministerial Meeting on Accelerating actions for implementation of Decade of Action for Road Safety. Hal 148 